\title{
COMUNICAÇÃO ORGANIZACIONAL E FUTEBOL: ANÁLISE DAS ESTRATÉGIAS COMUNICATIVAS DO GRÊMIO GAVIÕES DA FIEL
}

\author{
NÚBIA AZEVEDO \\ UNIVERSIDADE FEDERAL DE OURO PRETO \\ OURO PRETO, MINAS GERAIS, BRASIL \\ NUBIAAZEVEDOLHP@GMAIL.COM \\ NAIR PRATA \\ UNIVERSIDADE FEDERAL DE OURO PRETO \\ OURO PRETO, MINAS GERAIS, BRASIL \\ NAIRPRATA@UOL.COM.BR
}

HTTP://DX.DOI.ORG/10.5902/2316882X27890 
COMUNICAÇÃO ORGANIZACIONAL E FUTEBOL: ANÁLISE DAS ESTRATÉGIAS COMUNICATIVAS DO GRÊMIO GAVIÕES DA FIEL

Resumo: Com a transformação do futebol em negócio, e cada vez mais independentes do clube que representam, tornando-se fundamental uma imagem positiva para sua manutenção, a comunicação organizacional passou a ter grande importância para as torcidas organizadas. Assim, o presente artigo busca analisar os meios de comunicação do Grêmio Gaviões da Fiel, investigando a maneira como a torcida se comunica com seu público.

Palavras-Chave: comunicação organizacional; torcida organizada; Gaviões da Fiel.

\section{COMUNICACIÓN ORGANIZACIONAL Y FÚTBOL: ANÁLISIS DE LAS ESTRATEGIAS COMUNICATIVAS DEL GREMIO GAVIÕES DA FIEL}

Resumen: Con la transformación del fútbol en un negocio, y cada vez más independientes del club que representan, haciéndose fundamental una imagen positiva para su mantenimiento, la comunicación organizacional pasó a tener gran importancia para las hinchadas organizadas. Por lo anterior, este artículo busca examinar los medios de comunicación del Gremio Gaviões de Fiel, analizando la manera como la hinchada se comunica con su público.

Palabras-clave: comunicación organizacional; hinchadas organizadas; Gaviões da Fiel.

ORGANIZATIONAL COMMUNICATION AND SOCCER: ANALYSIS OF THE COMMUNICATION STRATEGIES OF THE GRÊMIO GAVIÕES DA FIEL

Abstract:With the transformation of soccer into a business, and becoming more and more independent of the club they represent, making it a fundamental positive image for its maintenance, organizational communication has become of great importance for organized crowd. Like this, the present article search to analyze the communication media of Gaviões da Fiel, investigating the way the crowd communicates with your audience. Keywords: organizational communication; organized crowd; Gaviões da Fiel. 


\section{INTRODUÇÃO}

A comunicação organizacional vem adquirindo crescente importância na gestão das organizações contemporâneas, representando um dos alicerces do desenvolvimento da organização. Nesse contexto, as empresas, o mercado de comunicação e as organizações em geral passam a gerenciar esse setor de maneira mais abrangente e efetiva.

O Brasil tem presenciado, em paralelo, a transformação do esporte, antes considerado uma atividade de lazer, em um negócio lucrativo para as organizações desportivas. O futebol é, neste contexto, a principal vertente da indústria esportiva. Assim, com este esporte cada vez mais midiático e transformado em negócio, a comunicação organizacional se tornou uma grande preocupação das organizações desportivas.

Uma imagem organizacional positiva será responsável por trazer às organizações desportivas o interesse de investidores e dos próprios torcedores em consumir produtos e serviços relacionados ao clube. Tendo a imagem se tornado tão importante para as organizações desportivas, surgiu a ideia deste estudo. A proposta é analisar a forma como a Gaviões da Fiel, maior torcida organizada do País, comunica-se com o seu público.

\section{COMUNICAÇÃO ORGANIZACIONAL E ORGANIZAÇÕES DESPORTI- VAS}

Até a Revolução Industrial, a sociedade produzia de maneira artesanal. A partir de meados do século XVIII, com o surgimento da máquina a vapor, o esforço humano foi substituído por grandes aparelhos, e é neste contexto que surgem as organizações. Ao buscar um breve conceito de organização, surgem diversas definições. Segundo Oliveira (2001, p.68), "desde o passado mais remoto, nossos ancestrais aprenderam a juntar esforços para atingir objetivos". Foi da união destes esforços que nasceram as organizações.

As organizações podem ser classificadas por diferentes critérios. Para Hall (2004), "são as características organizacionais que deveriam servir como base classificatória das organizações" (p. 36). Algumas variáveis aparentam ser importantes em uma iniciativa classificatória, como a variável relativa ao tamanho, a variável pública ou privada, orientadas ao lucro ou sem fins lucrativos, ou ainda a variável segundo a área da sociedade em que atuam: educacional, saúde, agrícola, lazer e etc.

Rev.Cad.Comun. Santa Maria, v.21, n.3, art 2, p. 35 de 51, set/dez.2017 
Considerando a variável segundo o setor da sociedade em que atuam, existem as organizações voltadas para o lazer e o entretenimento. Nesta categoria podem ser inseridas as organizações desportivas, como os clubes de futebol, as federações e as torcidas organizadas. Atualmente, esses clubes esportivos não são voltados somente para o entretenimento, já que foram transformados em clubes-empresa. Barbosa e Batista (2014) mostram que a Lei Pelé, instituída em 24 de março de 1998, "concretizou a proposta de implementação do clube empresa" (p. 15).

Surge assim a necessidade de se implantar características empresariais, não só na diretoria, mas em todos os setores administrativos das organizações esportivas. Nesta mudança, o setor de comunicação sofreu grandes alterações. Para Baldissera (2000), "é possível afirmar que a organização é um processo de construção que tem, na base, o processo de comunicação" (p. 18). Já Farias (2009) recorre a Kunsch para quem a comunicação organizacional é "a disciplina que estuda como se processa o fenômeno comunicacional dentro das organizações no âmbito da sociedade global. Ela analisa o sistema, o funcionamento e o processo de comunicação entre a organização e seus diversos" (p.55).

De acordo com Almeida (2008), os grandes clubes do futebol brasileiro têm a preocupação de consolidar o departamento de marketing, mas não levam em consideração a comunicação institucional. "Basicamente, o departamento de comunicação dos clubes de futebol do Brasil atende à necessidade do dia-a-dia da imprensa - organização de coletivas, preparação de clipping, marcação de entrevistas exclusivas ou matérias especiais" (p.44).

Nas demais organizações esportivas, o quadro é o mesmo. As torcidas organizadas, por exemplo, têm se tornando cada vez mais independentes dos clubes que representam, com número de associados aumentando rapidamente. Como a comunicação organizacional visa a formação da reputação, de uma boa imagem da empresa junto aos seus públicos, esta passou a ser fundamental para a venda de produtos oficiais, realizações de eventos e demais estratégias que tornam possível a manutenção das torcidas. 


\section{FUTEBOL: UMA PAIXÃO DOS BRASILEIROS}

O esporte que se tornou paixão brasileira tem seus primórdios, segundo Galeano (2004), há cinco mil anos, quando os chineses já brincavam com a bola nos pés. Estes jogos de bola ainda não eram o futebol, uma vez que não havia definição de regras, como atualmente. No entanto, na Itália medieval surgiu o giocodel cálcio, um jogo disputado por 27 jogadores em cada equipe, que tinha por objetivo conduzir a bola até dois postes que ficavam nos cantos extremos das praças onde o jogo era praticado. Por volta do século XVII, o giocodel cálcio chegou à Inglaterra, onde ganhou novas regras, tornando-se um jogo organizado e sistematizado.

O futebol se profissionalizou em 1885, um ano antes da fundação da International Board, entidade responsável por estabelecer e mudar as regras deste esporte, quando necessário. Criado na Inglaterra, este órgão ainda é, nos dias atuais, o único responsável por essas mudanças de regras.

No Brasil, o futebol surgiu pelas mãos de Charles William Miller. Nascido no bairro paulistano do Brás, aos nove anos de idade ele viajou para a Inglaterra para estudar, e lá teve o primeiro contato com o futebol. Vestiu a camisa do Corinthian Team, time amador inglês, que mais tarde inspirou a fundação do Corinthians Paulista. Miller retornou ao Brasil, em 1894, trazendo na bagagem a primeira bola de futebol do País e um conjunto de regras.

O primeiro jogo de futebol no Brasil aconteceu entre os funcionários ingleses da ferrovia São Paulo Raiway e de uma empresa de serviço público, a Companhia do Gás, no dia 15 de abril de 1895. "Este foi o primeiro grande jogo, aquele que empolgou a plateia, foi realizado em São Paulo, [...] na presença de sessenta torcedores" (CALDAS, 1988, pp. 15-16).

O futebol no Brasil faz parte da identidade, é tido como um elemento que representa a cultura nacional. A mídia tem papel de destaque na popularização do futebol e na transformação deste em parte da identidade do povo brasileiro. É a mídia também a responsável por associar, muitas vezes, torcida a nação. É comum os locutores e comentaristas usarem expressões como "a nação colorada empurrou o time até o final", "a equipe argentina sentiu a pressão da nação alvinegra", e assim por diante. Para Guerra (2000), é assim que o conceito de viver em uma pátria de chuteiras é adotado. 
Sendo assim, algumas questões simbólicas e ritualísticas podem ser notadas no futebol. Ao falar em símbolos e ritos, Roberto DaMatta (1982) destaca que os rituais são divididos em diferentes categorias, como ritos de passagem ou ritos de adoração. Os ritos de adoração seriam aqueles que demonstram devoção em relação a algo, e no futebol temos um grande exemplo: as torcidas organizadas.

Por meio da ideologia e das atitudes dos torcedores estas agremiações simbolizam o amor e a lealdade eterna ao clube que representam. Muitas vezes, esse sentimento é exaltado em cantos, como o hino do Atlético Mineiro ("Clube Atlético Mineiro, uma vez até morrer") ou nos lemas das próprias torcidas, como é o caso do objeto de estudo deste trabalho, a Gaviões da Fiel, que tem como lema "Lealdade, Humildade e Procedimento".

A mídia é também grande precursora de outra linha seguida pelo futebol, a de caráter empresarial, que envolve os meios de comunicação, as propagandas, o futebol-empresa e os serviços em geral. Leoncini (2005) destaca que os anos 1990 assistiram "a uma série de mudanças na administração do futebol, pelo estabelecimento de contratos de parceria entre clubes e empresas para a gestão comercial dos clubes" (p. 14). Neste contexto, a co-gestão, em 1992, entre o Palmeiras, clube de futebol tradicional de São Paulo e a Parmalat, uma empresa de laticínios que tinha como objetivo ganhar visibilidade no mercado pode ser considerada como grande marco da transformação do futebol brasileiro em empresa.

De acordo com Barbosa e Batista (2014), ainda na década de 1990, a legislação futebolística sofreu grandes impactos em decorrência de algumas leis instituídas. A primeira foi a Lei $n^{\circ} 8.672$, mais conhecida como Lei Zico, instituída em 1993. "Esta norma propunha a transformação dos clubes de futebol em sociedades comerciais, clubes-empresa” (p. 14). Essa lei foi substituída, em 1998, pela Lei n 9.615, a Lei Pelé, que consolidou a transformação dos clubes de futebol em clubes-empresa. Com relação às leis que alteraram a legislação futebolística, as autoras destacam, por fim, que algumas imperfeições foram encontradas na Lei Pelé, fazendo com que esta fosse substituída pela Lei n 9.981, em 2000.

O futebol movimenta, nos dias atuais, entre $R \$ 455$ bilhões e $R \$ 577$ bilhões anualmente no mundo. Reconhecido como o país do futebol, o Brasil, no entanto, tem participação mínima na receita mundial. De acordo com o Ministério dos Esportes o Brasil ganha apenas 2\% do total do mercado global. A Inglaterra, principal ganhador, fica com 30\% do valor total.

Rev.Cad.Comun. Santa Maria, v.21, n.3, art 2, p. 38 de 51, set/dez.2017 
De acordo com a Pluri Consultoria, o futebol brasileiro movimenta cerca de $\mathrm{R} \$ 40$ bilhões. A liga de futebol inglesa tem, sozinha, um faturamento anual de aproximadamente $\mathrm{R} \$ 9,4$ bilhões ${ }^{1}$.

A mídia possui também grande participação no faturamento dos clubes por meio das cotas de direitos televisivos. Como Ekelund apud Leoncini (2005) destaca, é a devoção de sua torcida e o número de torcedores que o clube tem que influenciará no valor que a equipe irá receber de cotas televisivas. A partir de 2016, a previsão é que os times de maior torcida no Brasil, Flamengo e Corinthians respectivamente, recebam cerca de $\mathrm{R} \$ 170$ milhões por $\mathrm{ano}^{2}$.

Sendo assim, o Sport Club Corinthians Paulista é, hoje, um dos clubes mais valiosos do País, estando também entre os times que mais recebem cotas de televisão, devido a sua grande torcida.

\section{SPORT CLUB CORINTHIANS PAULISTA}

Um dos maiores clubes do futebol nacional, o Corinthians, foi fundado em 1910. No bairro do Bom Retiro, por volta das $20 h 30$ do dia $1^{\circ}$ de setembro, os pintores de parede Antônio Pereira e Joaquim Ambrósio, o sapateiro Rafael Perrone, o trabalhador braçal Carlos Silva e o motorista Anselmo Correia decidiram fundar um clube de futebol "que pudesse praticar o nobre esporte sem perder suas raízes da massa, do povo humilde e trabalhador ao qual pertenciam" (MARTINEZ, 2010, p. 11).

O nome do time do Bom Retiro foi decidido graças a um jogo do Corinthian Team visto por esses cinco amigos. A equipe inglesa realizou, a convite do Fluminense, uma excursão pelo Brasil e conquistou, com maestria, seis vitórias. Maravilhado com a atuação de gala do time inglês, Joaquim Ambrósio sugeriu o nome de Corinthians, com a letra "s" no final.

Nos anos seguintes, o Corinthians se tornou um dos times mais respeitados da várzea paulistana e, em 1913, após passar por dois jogos eliminatórios, a equipe foi aceita na Liga Paulista de Futebol. Com o passar dos anos a equipe do Bom Retiro foi acumulando campeonatos paulistas

1 Fonte: Site O Globo (http://oglobo.globo.com/brasil/brasil-movimenta-apenas-2-do-mercado-da-bola-13026765) matéria publicada em 26 de junho de 2014.

2 Fonte: Site Futebol Business (http://futebolbusiness.com.br/direitos-de-transmissao/) Acesso em 17 mar. 15

Rev.Cad.Comun. Santa Maria, v.21, n.3, art 2, p. 39 de 51, set/dez.2017 
e conquistas patrimoniais. Em 1926 aconteceu a aquisição do terreno do Parque São Jorge, já em 1940 foi inaugurada aquela que, até pouco tempo, foi a sua casa, o estádio Pacaembu. Como conta Martinez (2010), na década de 1950 o Corinthians viveu os seus anos dourados, tendo como destaque a eleição do lendário presidente Vicente Matheus em 1959.

Entretanto, como as dificuldades estão sempre presentes na história do Sport Club Corinthians Paulista, em 1955, teve início o período mais sofrido da já centenária vida corinthiana. Foram 22 anos, oito meses e sete dias sem conquistar um título de expressão. Os anos 1960 ficaram marcados pelo maior deslocamento humano do futebol, episódio conhecido como a "Invasção Corinthiana". Mais de setenta mil torcedores corinthianos invadiram o Rio de Janeiro para assistir, no dia 5 de dezembro de 1976, a partida entre Fluminense e Corinthians, no Maracanã.

No ano seguinte, o Corinthians põe fim ao período sem títulos e conquista o Paulistão 1977, vencendo a Ponte Preta por 1xo no dia 13 de outubro. Na década de 1980 o clube viveu a Democracia Corinthiana. De acordo com o site oficial do time paulista, "o movimento visava maior participação dos jogadores e demais empregados do clube nas decisões do Departamento de Futebol"3.

Um dos momentos mais marcantes da história do clube do Parque São Jorge acontece em 2006, quando a parceria com a Media Sports Investments, a MSI, entra em crise. A origem do dinheiro da empresa começa a ser investigada e sérias acusações contra Alberto Dualib e Nesi Curi, então presidente e vice-presidente do clube, colocam fim à parceria, que deixa o Corinthians com uma dívida de 90 milhões de reais ${ }^{4}$. Os escândalos se refletiam dentro de campo e o Corinthians termina o ano brigando para não ser rebaixado no campeonato nacional.

No ano seguinte, 2007, a equipe não consegue se salvar e vive o pior episódio de sua história: o rebaixamento à série $B$ do campeonato brasileiro. Na Série B o Corinthians realizou ótima campanha, conquistando o

3 Fonte: Site oficial do Corinthians (http://www.corinthians.com.br/site/clube/historia/) Acesso em 22 maio 2015.

4 Fonte: Site MeuTimão.com (http://www.meutimao.com.br/historia-do-corinthians/fatos-marcantes/a_era_msi) Acesso em 25 maio 2015

Rev.Cad.Comun. Santa Maria, v.21, n.3, art 2, p. 40 de 51, set/dez.2017 
título com quatro rodadas de antecedência ${ }^{5}$. O ano de 2010 não trouxe ao Corinthians nenhum título, mas foi de muitas festas. O clube comemorou o seu centenário. No dia $1^{\circ}$ de setembro, mais de $100 \mathrm{mil}$ "loucos do bando" lotaram o Anhangabaú, em São Paulo, para as comemorações de aniversário do Timão.

A equipe do Parque São Jorge acumulou durante os seus 106 anos de história diversas conquistas marcantes, como o bicampeonato brasileiro em 1998/1999 em cima dos mineiros Cruzeiro e Atlético, respectivamente, além do tetracampeonato em 2005, sob o comando de um dos principais ídolos do clube, Carlitos Tevez. Em 2000 a equipe conquistou o Mundial de Clubes, título polêmico, porém reconhecido pela FIFA. Em 2012 o Corinthians conquista o tão sonhado título da Libertadores da América de forma invicta, e mais um Mundial de Clubes.

Em 2014 o time do Parque São Jorge realiza mais um sonho de sua torcida ao inaugurar, em Itaquera, bairro da zona lesta de São Paulo, o seu estádio, a Arena Corinthians. Para Piovan e Cesar (2012), a torcida sempre foi a maior conquista do Sport Club Corinthians Paulista. "Sempre foi única, desde a sua fundação. Claro, no princípio, o número de torcedores era ínfimo, não havia torcida organizada, nada disso. Depois, já no Parque São Jorge, os grupos se uniam, não com o espírito de uma torcida organizada" (PIOVAN e CESAR, 2012, p. 245).

\section{GAVIÕES DA FIEL}

No Brasil, o país do futebol, na maioria das vezes já se nasce um torcedor e cresce aprendendo a acompanhar, apoiar e amar aquele que se torna o time do coração. As torcidas organizadas são conhecidas por essa dedicação, por acompanhar o clube onde ele for jogar.

De acordo com o Artigo $2^{\circ}$ do Estatuto do Torcedor, torcida organizada é "a pessoa jurídica de direito privado ou existente de fato, que se organize para o fim de torcer e apoiar entidade de prática esportiva de qualquer natureza ou modalidade" ${ }^{6}$, e, como destaca o Artigo $2^{\circ}$-A, está obrigada a

5 Fonte: Site oficial do Corinthians (http://www.corinthians.com.br/site/clube/historia/) Acesso em 26 maio 2015.

6 Fonte: Estatuto do Torcedor (http://www.planalto.gov.br/ccivil_03/leis/2003/ 110.671.htm) Acesso em: 6 maio 2015.

Rev.Cad.Comun. Santa Maria, v.21, n.3, art 2, p. 41 de 51, set/dez.2017 
manter cadastro de seus associados ou membros, contendo informações como: endereço, CPF, profissão, estado civil, fotografia, entre outros.

Por meio do futebol, os torcedores experimentam diversos sentimentos e sensações que desencadeiam as paixões pelos times, pelos jogadores. Neste contexto, Diehl (2014) coloca que "essa emoção apaixonada pode ser só uma diversão, mas também beira, por muitas vezes, o fanatismo" (p. 27).

Chegamos, então, à outra face das torcidas organizadas, a violência. Elias e Dunning apud Amaro et al (2012) destacam a índole dos torcedores, a visibilidade proporcionada pelos meios de comunicação e as canções criadas pelas torcidas como prováveis motivações da violência.

Em caso mais recente, a maior organizada do Palmeiras, a Mancha Verde, e a maior organizada do rival Corinthians, a Gaviões da Fiel, protagonizaram, em agosto de 2014, uma briga em que um torcedor foi espancado e morreu no hospital7. Outro caso emblemático da violência das torcidas organizadas, envolvendo o objeto deste estudo, a Gaviões da Fiel, foi a morte do garoto boliviano Kevin Espada, em fevereiro de 2013, após ser atingido por um sinalizador disparado por um membro da organizada corinthiana8.

A história do Grêmio Gaviões da Fiel começou no dia $1^{\circ}$ de julho de 1969, quando um grupo de jovens se reunia nas arquibancadas, durante os jogos, para debaterem os rumos políticos do Sport Club Corinthians Paulista. A fundação aconteceu no momento em que o Brasil vivia sob a ditadura militar. Jovens torcedores iniciaram uma cobrança na administração de um dos maiores clubes do Brasil, em uma época em que não existia liberdade de expressão?.

Já estava decido que Fiel faria parte do nome, afinal o torcedor corinthiano já era conhecido desta maneira. De acordo com o site oficial da

7 Fonte: Site G1 (http://g1.globo.com/sao-paulo/noticia/2014/08/palmeirense-agredido-em-briga-com-corintianos-tem-morte-cerebral.

8 Fonte: Site Globo Esporte (http://globoesporte.globo.com/futebol/times/corinthians/noticia/2013/02/torcedor-boliviano-morre-atingido-por-sinalizador-diz-policia-local.html) matéria publicada em 20 fev. 2013. Acesso em 16 maio 2015.

9 Fonte: Site oficial da Gaviões da Fiel (http://www.gavioes.com.br/p/historia) Acesso em: 17 de mar. 2015 
torcida, o Gavião foi escolhido como símbolo devido as suas características. Este animal é a ave que voa mais alto, enxerga mais longe, não erra a presa e não possui um predador natural. Nascia então a Gaviões da Fiel, maior torcida organizada do Corinthians Paulista e maior torcida organizada brasileira.

Dentro da torcida há uma estrutura administrativa, organizacional hierarquizada, tendo um presidente, vice-presidente, $1^{\circ}$ secretário, $2^{\circ}$ secretário, $1^{\circ}$ tesoureiro, $2^{\circ}$ tesoureiro e um diretor financeiro ${ }^{10}$. Estes cargos podem ou não ser remunerados, sendo pagos, na maioria das vezes, com a venda de produtos da torcida e com o que é arrecadado com as mensalidades dos torcedores associados.

A ideologia política está atrelada aos Gaviões desde o momento de sua fundação. Na década de 1970, a torcida esteve envolvida nos gritos pela democracia que ganharam as ruas do País e foi a primeira torcida a levar para um estádio uma faixa falando em anistia. Outra preocupação dos Gaviões, desde a fundação, é a questão social. Em entrevista para o site Repórter Social, publicada em 30 de junho de 2005, Wildner Paula Rocha, o Pulguinha, na época vice-presidente e diretor social da Gaviões, diz que a busca pela justiça social é obrigação de qualquer organização"

No que tange a face violenta das torcidas organizadas, Gomes e Martins (2014) recordam um difícil momento enfrentado pelos Gaviões. Após confronto contra vascaínos, no estádio Mané Garrincha, em Brasília, em agosto de $2013^{12}$, mais um pedido de extinção da Gaviões da Fiel foi feito pelo Ministério Público. Em manifesto apresentado pela maior organizada do País, foi citado um estudo da pesquisadora e autora do livro Futebol e Violência, Heloísa Reis:

10 Fonte: Site oficial da Gaviões da Fiel (http://www.gavioes.com.br/index.php/os-gavioes/diretoria/) Acesso em: 27 de maio. 2015

11 Fonte: Blog do Pulguinha (http://blogpulguinha.blogspot.com.br/2008/07/tu-precisa-ouvir-isso.html) Acesso em: 27 de mar. 2015

12 Fonte: Site Globo Esporte (http://globoesporte.globo.com/futebol/brasileirao-serie-a/noticia/2013/08/corintianos-tentam-atacar-vascainos-e-provocam-confusao-em-brasilia.html) Acesso em: 28 de maio 2015. 
Torcidas organizadas agora recebem o rótulo de facções. É uma clara tentativa de relacioná-las ao mundo do crime, como se todas as suas atitudes fossem ilícitas. Mas a realidade é diferente. $O$ torcedor organizado não é bandido. Ele trabalha (a média de desemprego nas torcidas é de $2,8 \%$ em comparação com os $8,1 \%$ da média brasileira), mora com os pais $(86,8 \%)$ e tem um significativo grau de instrução ( $80,8 \%$ possuem de 10 a 12 anos de escolaridade). Esses números fazem parte do resultado de uma pesquisa que realizei com 813 integrantes das três maiores organizadas de São Paulo. São dados que desmentem a visão de que seus filiados são vagabundos que se associam para o crime. (REIS apud GOMES; MARTINS, 2014, pp. 115-116).

\section{COMUNICAÇÃO ORGANIZACIONAL DO GRÊMIO GAVIÕES DA FIEL}

A Gaviões da Fiel, além do jornal O Gavião, da Rádio Livre Gaviões e do site oficial da torcida, usa as redes sociais digitais para se comunicar e proporcionar interação aos seus associados.

A metodologia utilizada para conduzir o estudo se fundamenta na pesquisa bibliográfica e documental, e na entrevista. A pesquisa bibliográfica consistirá no levantamento teórico sobre os assuntos abordados e a pesquisa documental, por sua vez, se constituirá de consultas feitas ao acervo da Gaviões da Fiel, na sede da torcida, localizada em São Paulo. Outro método de pesquisa a ser utilizado será a entrevista, realizada com o responsável pelo departamento de comunicação da torcida organizada.

Foi entrevistado o assessor de imprensa da Gaviões da Fiel, Alex da Matta, que também é o principal responsável pelo departamento de comunicação da torcida, em especial pela Rádio Livre Gaviões. Alex da Matta participa da produção e manutenção de todos os meios utilizados pela torcida organizada para se comunicar com seu público.

\subsection{SITE OFICIAL}

O site oficial da Gaviões da Fiel é o meio de comunicação que visa apresentar a torcida organizada. Informações como história, ideologia e o processo para se tornar um Gavião são encontrados facilmente no site. As informações são separadas por editorias, num total de oito: Home, Os Gaviões, Torcida, Carnaval, Corinthians, Multimídia, Contato e Loja.

O site oficial da Gaviões da Fiel é predominantemente preto e branco, cores símbolo do Corinthians, clube que representam, e as principais in-

Rev.Cad.Comun. Santa Maria, v.21, n.3, art 2, p. 44 de 51, set/dez.2017 
formações se encontram com clareza. $O$ endereço da sede da agremiação, telefone e e-mail para contato são disponibilizados aos visitantes, estão corretos e funcionam precisamente. Os links que aparecem na home do site também funcionam da maneira correta. Em sua entrevista, o assessor dos Gaviões, Alex da Matta, explicou que o site oficial está passando por uma reformulação e não está totalmente pronto, motivo pelo qual algumas informações ainda não foram colocadas.

\subsection{FACEBOOK}

O perfil da Gaviões da Fiel no Facebook teve seu inicio em maio de 2011 e atualmente é de responsabilidade do jornalista Alex da Matta. A página possui, hoje, 398.689 seguidores $^{13}$. Durante os sete dias analisados, foram realizadas 47 publicações, com atualizações diárias. A média de postagens durante os dias da análise é de 6,71 post por dia. As datas que mais possuem postagens são os dias de jogos, e, considerando apenas estes dias de maior fluxo, a média é de 9,0 posts por dia.

A quantidade de curtidas e compartilhamentos foram os indicadores usados para chegar às publicações que mais despertam o interesse dos seguidores. Sendo assim, observou-se que as notícias sobre vitórias, fotos dos Gaviões nos locais das partidas e anúncio dos eventos que ocorrem na quadra, como a tradicional feijoada nos sábados, são os assuntos que mais envolvem os seguidores. Durante todo o período analisado não foi realizada nenhuma mudança no layout da página. As imagens usadas não são alteradas em datas comemorativas ou campanhas especiais, sendo mantida assim a identidade da fanpage.

\subsection{TWITTER}

A Gaviões da Fiel participa do Twitter desde junho de 2010, e suas atualizações são também de responsabilidade do jornalista Alex da Matta, com a colaboração da Natália Zanotti, funcionária do departamento de comunicação da torcida. A página possui hoje 318 mil seguidores e 22 mil tweets ${ }^{14}$.

Durante os sete dias de análise foram publicados 27 tweets, sendo que

13 Dados obtidos dia 20/03/2017.

14 Dados obtidos dia 20/03/2017.

Rev.Cad.Comun. Santa Maria, v.21, n.3, art 2, p. 45 de 51, set/dez.2017 
a página ficou sem atualização apenas na sexta-feira, 27 de novembro. A média de publicações durante os dias da análise é de 3,8 tweets por dia. A exemplo do Facebook, os dias de jogos são as datas com mais fluxo, tendo como média específica 7,5 tweets por dia. No caso do Twitter, a quantidade de favoritos e retweets foram os indicadores usados para chegar aos posts que mais despertam o interesse dos seguidores. Sendo assim, os assuntos que possuem maior apelo são as comemorações das vitórias do Corinthians, fotos da torcida nos locais dos jogos e dados das partidas como ficha técnica e escalação dos jogadores. No Twitter, assim como no Facebook, durante todo o período analisado não foi realizada nenhuma mudança no layout da página. As imagens usadas não são alteradas sendo mantida assim a identidade da fanpage.

\subsection{RÁDIO LIVRE GAVIÕES}

A rádio Livre Gaviões foi um projeto da torcida organizada que teve seu início em maio de 2005. Segundo Alex da Matta, até o final de 2012 a rádio contava apenas com uma programação própria, com notícias da quadra e do Corinthians. A partir de novembro foi firmada uma parceria com a Rádio Coringão, possibilitando maior variedade na grade de programação.

A Rádio Livre Gaviões transmite conteúdo 24 horas por dia e sete dias por semana. A programação é mais informal, descontraída e flexível, sofrendo alterações sem a necessidade de aviso prévio aos ouvintes. Nos momentos em que não ocorrem transmissões de partidas ou eventos realizados na quadra dos Gaviões, a programação é composta por reprodução de músicas com alguns intervalos comercias e boletins informativos do Corinthians. A linguagem utilizada pelos apresentadores é informal, e não existe censura em relação às gírias. A partir da análise feita das transmissões de jogos, observa-se o uso comum de alcunhas para se referir ao clube, como o todo poderoso Timão ou Coringão.

\subsection{JORNAL O GAVIÃO}

O jornal O Gavião, de acordo com Gomes e Martins (2014), foi lançado por volta de 1977, quando os Gaviões inauguraram a primeira quadra, já no Bom Retiro, bairro da cidade de São Paulo. Desde então, foram 62 edições publicadas, voltadas não só para os associados da Gaviões, mas para os

Rev.Cad.Comun. Santa Maria, v.21, n.3, art 2, p. 46 de 51, set/dez.2017 
corinthianos em geral.

Alex da Matta, responsável pelo departamento de comunicação da torcida organizada, relata que o jornal é distribuído por diversas regiões da capital paulista, chamadas de "quebradas". Os pontos de encontro oficiais da Gaviões e as sub-sedes em diversas cidades também recebem exemplares do jornal, inclusive a sub-sede do Japão. São distribuídos entre 3 e 10 mil exemplares por edição, dependo da importância do tema.

Além do Alex, a equipe do jornal conta, hoje, com mais quatro pessoas, Natália Zanotti, Jerry Xavellier, Gustavo Guimarães e Érika Papangelacos, todas do departamento de comunicação da torcida organizada. O jornal sai de acordo com datas especiais, como aniversários da agremiação, aniversários do Corinthians e títulos importantes.

Duas edições foram escolhidas para análise: Edição N 58 - Fevereiro/ Março de 2013 e a Edição № 62 - Julho de 2015. O jornal O Gavião apresenta um projeto gráfico constante de edição para edição, e mantem o mesmo tamanho, com quatro páginas. O formato em PDF disponibilizado no site oficial da torcida organizada é exatamente igual ao impresso distribuído na sede e demais pontos de encontro. As duas edições analisadas apresentaram, na primeira página, o logo do jornal onde aparecem informações como o site oficial da torcida, o número da edição, mês e ano da publicação.

A linguagem utilizada é a mais simples possível, e busca atingir sempre o objetivo da comunicação de torcedor para torcedor, ressaltando o sentimento de união. Os verbos se apresentam na terceira pessoa do plural, sendo comum expressões como "nós, dos Gaviões da Fiel, [...]". O lado político da torcida organizada é sempre destacado no Jornal o Gavião, seja pela temática abordada, como a questão da elitização do futebol, ou por trechos que remetem à ideologia da entidade.

\section{CONSIDERAÇÕES FINAIS}

A partir da pesquisa realizada nos meios de comunicação da torcida organizada Gaviões da Fiel, pode-se apontar algumas estratégias comunicativas utilizadas. As páginas da torcida, além do jornal, rádio e site oficial, são administradas e produzidas pelo departamento de comunicação dos Gaviões da Fiel, composto por cinco profissionais da área de Comunicação. Nota-se um grande empenho em atualizar as páginas da torcida nas 
redes sociais, que recebem, em média, seis publicações por dia no caso do Facebook, e três no que diz respeito ao Twitter.

Contudo, as organizações esportivas ainda investem pouco em comunicação organizacional, e, no que diz respeito à torcida organizada Gaviões da Fiel, o motivo pelo qual a gestão não trabalha a imagem institucional de maneira mais eficaz é a falta de recursos financeiros. A dificuldade de se conseguir apoio devido à frequente associação destas torcidas à violência é apontada por Alex como principal motivo para não se conseguir manter mais profissionais no departamento de comunicação.

Por este motivo, buscar aumentar o número de associados é de extrema importância para a torcida organizada. Neste contexto, Diehl (2014) afirma que a condição de fã do torcedor, por si só, não faz dele um consumidor em potencial. Sendo assim, as organizações desportivas têm sido, cada vez mais, pressionadas a criar estratégias de marketing para manter estes torcedores. Neste quesito, o Grêmio Gaviões da Fiel acaba por perder uma grande oportunidade de fortalecer a marca, uma vez que, até então, faz pouco uso do marketing esportivo.

Outro ponto que apresenta falhas é a comunicação com o seguidor das páginas nas redes sociais digitais. Muitas das dúvidas dos torcedores e associados não são respondidas pela torcida organizada, e, em alguns casos, o pedido de interação atendido pelo seguidor não tem retorno dos Gaviões da Fiel.

Conclui-se que a torcida organizada possui uma boa relação com o torcedor, principalmente por meio do Facebook, pois busca sempre atualizar os seguidores com novidades sobre a torcida e o clube que representa, e da Rádio Livre Gaviões, uma vez que é o meio de comunicação dos Gaviões que mais interage com o torcedor devido a disponibilização do Whatsapp.

Como observado no referencial teórico, pode-se notar a crescente preocupação da Gaviões da Fiel com a comunicação organizacional, com a imagem institucional, e com os benefícios que esta melhora na imagem da organização pode acarretar. Os Gaviões também fazem uso dos seus meios de comunicação para rebater críticas que recebem e lutar por meIhorias para o torcedor de forma geral, não só para o associado.

Por meio de toda a análise, foi possível perceber em quais pontos o Grêmio Gaviões da Fiel poderia evoluir. A torcida pode aprimorar sua relação concedendo mais atenção aos questionamentos e interações dos seguidores, além de utilizar a identidade visual das páginas para campanhas

Rev.Cad.Comun. Santa Maria, v.21, n.3, art 2, p. 48 de 51, set/dez.2017 
que despertem maior engajamento do público.

Este trabalho faz-se relevante para entender como uma torcida organizada pode aproveitar o envolvimento natural de seu público-alvo para divulgar sua marca e expandir o quadro de associados, proporcionando cada vez mais uma melhor estrutura para a organização.

\section{REFERÊNCIAS}

ALMEIDA, Bruno Puopolo. Futebol e Comunicação Organizacional: A importância da comunicação institucional dos grandes clubes do país - o exemplo do São Paulo Futebol Clube. 2008. 128 f. Trabalho de Conclusão de Curso (Pós-Graduação) - Universidade de São Paulo, São Paulo, 2008.

AMARO, Fausto; et al. Comunicabilidade entre torcidas organizadas em estádios de futebol: Cantos de louvor ou cantos de guerra? In:XXXV Congresso Brasileiro de Ciências da Comunicação, 2012, Fortaleza. Anais eletrônicos... Fortaleza: Intercom, 2012. Disponível em: <http://www.intercom.org.br/papers/nacionais/2012/resumos/R7-04671.pdf >. Acesso em 15 abril 2015.

BALDISSERA, Rudimar. Comunicação organizacional: o treinamento de recursos humanos como rito de passagem. São Leopoldo: UNISINOS, 2000.

BARBOSA, Isadora Rabello; BATISTA, Ana Luiza da Silva Oliveira. As crises nos times de futebol: Estratégias das assessorias de imprensa do Clube Atlético Mineiro e do Cruzeiro Esporte Clube. 2014. 92 f. Trabalho de Conclusão de Curso (Graduação) - Universidade Federal de Ouro Preto, Ouro Preto, 2014.

BEZERRA, Patrícia Rangel Moreira. O Futebol Midiático: Uma reflexão crítica sobre o jornalismo esportivo nos meios eletrônicos. 2008. 151 f. Trabalho de Conclusão de Curso (Mestrado) - Faculdade de Comunicação Social Cásper Líbero, São Paulo, 2008.

CALDAS, Waldenyr. O pontapé inicial. Contribuição à memória do futebol brasileiro. Tese delivre docência. São Paulo: ECA/USP, 1988, pp. 15-16

DA MATTA, Roberto. (org.) Universo do Futebol. Rio de Janeiro: Pinakotheke. 1982.

DIEHL, Danielle. Relacionamento com o torcedor: As estratégias comunicativas do XV de Piracicaba no Facebook. 2014. 77 f. Trabalho de Conclusão de Curso (Graduação) -Universidade Federal de Ouro Preto, Ouro Preto, 2014. 
DUARTE, Orlando. O Corinthians volta ao seu lugar. São Paulo: Companhia Editora Nacional, 2008.

DUARTE, Orlando; TURETA, João Bosco. Corinthians: O time da Fiel. São Paulo: Companhia Editora Nacional, 2008.

FARIAS, Luiz Alberto. $O$ campo acadêmico do ensino e da pesquisa em comunicação organizacional e relações públicas no Brasil. In: KUNSCH, Margarida M. Krohling (Org.). Comunicação Organizacional: Histórico, fundamentos e processos. São Paulo: Saraiva, 2009.

GALEANO, Eduardo. Futebol ao sol e à sombra. Porto Alegre: Ed. L\&PM Pocket, 2004.

GOMES, Érica; MARTINS, Daniela. Gaviões da Fiel - 45 anos: A história da maior torcida organizada do país. São Paulo: Produção independente, 2014.

GUERRA, Márcio. Você, ouvinte, é a nossa meta - A importância do rádio no imaginário do torcedor de futebol. Rio de Janeiro: Etc, 2000.

GUERRA, Márcio. Rádio x TV: o jogo da narração - A imaginação entra em campo e seduz o torcedor. Juiz de Fora: Juizforana Gráfica e Editora, 2012.

HALL, Richard. Organizações: estrutura e processos. Rio de Janeiro: Prentice Hall do Brasil, 1984.

KUNSCH, Margarida Maria. (ORG.). Comunicação Organizacional: Histórico, fundamentos e processos. São Paulo: Saraiva, 2009.

LEONCINI, Marvio P. ; SILVA, Márcia T. da. Entendendo o futebol como um negócio: um estudo exploratório.

MARTINEZ, André. Centenário do Corinthians. São Paulo: Larousse, 2010.

OLIVEIRA, Gercina A. de. Espaços Racionais. In: MOSCOVICI, Fela. A organização por trás do espelho: reflexos e reflexões. Rio de Janeiro: José Olympio, 2001.

PIOVAN, Marco; CESAR, Newton. Corinthians Eterna Paixão. São Paulo: Magma, 2012. 


\section{Núbia Azevedo}

Mestranda do Programa de Pós-Graduação em Comunicação da Universidade Federal de Ouro Preto (UFOP). Pesquisadora do grupo de pesquisa ConJor - Convergência e Jornalismo da Universidade Federal de Ouro Preto (UFOP). E-mail: nubiaazevedolhp@gmail.com

\section{Nair Prata}

Doutora em Linguística Aplicada (UFMG), professora do Programa de Pós-Graduação em Comunicação da Universidade Federal de Ouro Preto (UFOP), diretora Regional Sudeste da Intercom e vice-presidente da Associação Brasileira de Pesquisadores de História da Mídia (Alcar).

E-mail:nairprata@uol.com.br

RECEBIDO EM: 28/07/2017

ACEITO EM: 26/09/2017 